\title{
Comorbidity of Narcolepsy Type 1 With Autoimmune Diseases and Other Immunopathological Disorders: A Case- Control Study
}

\author{
Francisco Javier Martinez-Orozco ${ }^{\mathrm{a}}$, Jose Luis Vicario ${ }^{\mathrm{b}}$, Clara De Andres $^{\mathrm{c}}$, Miguel Fernandez-Arquero ${ }^{\mathrm{d}}$, \\ Rosa Peraita-Adrados ${ }^{\mathrm{e}, \mathrm{f}}$
}

\begin{abstract}
Background: Several evidences suggest that autoimmune diseases (ADs) tend to co-occur in an individual and within the same family. Narcolepsy type 1 (NT1) is a chronic sleep disorder caused by a selective loss of hypocretin-producing neurons due to a mechanism of neural destruction that indicates an autoimmune pathogenesis, although no evidence is available. We report on the comorbidity of ADs and other immunopathological diseases (including allergy diseases) in narcolepsy.
\end{abstract}

Methods: We studied 158 Caucasian NT1 patients $(60.7 \%$ male; mean age $49.4 \pm 19.7$ years), in whom the diagnosis was confirmed by polysomnography followed by a multiple sleep latency test, or by hypocretin-1 levels measurements.

Results: Thirty out of 158 patients $(18.99 \%$; 53.3\% female; 29 sporadic and one familial cases) had one or more immunopathological diseases associated. A control group of 151 subjects were matched by gender and age with the narcolepsy patients. Results demonstrated that there was a higher frequency of ADs in our series of narcolepsy patients compared to the sample of general population (odds ratio: 3.17; 95\% confidence interval: $1.01-10.07 ; \mathrm{P}=0.040$ ). A temporal relationship with the age at onset of the diseases was found.

Conclusions: Cataplexy was significantly more severe in NT1 patients with immunopathological diseases, and immunopathological diseases are a risk factor for severe forms of cataplexy in our series

Manuscript accepted for publication May 02, 2016

aSleep Unit, Clinical Neurophysiology Service, San Carlos University Hospital, Madrid, Spain

bHistocompatibility, Blood Center of the Community of Madrid, Madrid, Spain

${ }^{\mathrm{c}}$ Neurology Service, Gregorio Maranon University Hospital, Madrid, Spain 'Immunology Service, San Carlos University Hospital, Madrid, Spain

eSleep and Epilepsy Unit, Clinical Neurophysiology Service, Gregorio Maranon University Hospital, Madrid, Spain

${ }^{\mathrm{f} C}$ Corresponding Author: Rosa Peraita-Adrados, Sleep and Epilepsy Unit, Clinical Neurophysiology Service, Gregorio Maranon University Hospital, Complutense University of Madrid (UCM), C/ Dr. Esquerdo, 46, E-28007 Madrid, Spain.Email: rosa-peraita@telefonica.net

doi: http://dx.doi.org/10.14740/jocmr2569w (odds ratio: 23.6; 95\% confidence interval: 5.5 - 100.1).

Keywords: Autoimmune diseases; Comorbidity; Epidemiology; Immunopathological diseases; Narcolepsy with cataplexy; Narcolepsy type 1

\section{Introduction}

Narcolepsy is a chronic and rare sleep disorder, with an estimated prevalence of $0.03-0.16 \%$ of the World population [1]. Prevalence in Spain is considered to be similar to other European countries, as well as in North American population, ranging between $0.025 \%$ and $0.40 \%$ [2], but there are no epidemiological studies confirming these figures. The disease is caused by a deficiency in hypothalamic neurotransmission, through a selective loss of hypocretin-producing neurons [3, 4]. This mechanism of neural destruction potentially indicates an autoimmune pathogenesis, although the existence of a specific auto-antibody has not been demonstrated until now. Recently some papers have demonstrated that antibodies can be related with the disease [5-7].

Hypocretin-1 and 2 are two neuroexcitatory peptides produced in the dorsolateral region of the hypothalamus, with an important role in wakefulness and REM-sleep regulation. Some evidences support the autoimmune hypothesis of narcolepsy. Juji et al [8] were the first authors to describe a strong association with HLA-class II antigens. Today we know that DQB1*06:02 is the most strongly associated allele, in up to 98\% of cases, and the best HLA marker for the disease [9]. The complete haplotype classically associated with the disease is DRB1*15:01-DQA1*01:02-DQB1*06:02. A recent study in European population [10] confirmed the allele DQB1*06:02 as the principal risk factor for the disease (odds ratio (OR): 251). The estimated prevalence of DQB1*06:02 in Madrid area, where this study has been carried out, is $15 \%$ [11]. However, it remains unclear how a specific allele haplotype can induce an autoimmune response.

Other evidences are the discovery of three single nucleotide polymorphisms (SNPs) in the locus of the T-cell receptor- $\alpha$ (TCRA) on chromosome 14 [12]. The TCRA plays an important role in the recognition of peptides bound to HLA molecules, supporting the autoimmune hypothesis. The finding in 
2010 that hypocretin neurons co-express tribbles2 (Trib2) and narcolepsy patients diagnosed early after first symptoms have auto-antibodies against Trib2 also supported this hypothesis [13]. However, narcolepsy patients were negative for Trib2 antibodies close to disease onset [14], and today it has become clear that Trib2 auto-antibodies are unlikely to be the cause of the neuronal destruction.

The role of environmental factors as a trigger in genetically predisposed subjects has also been strongly suspected. Some studies have reported elevated anti-streptococcal antibodies in patients with recent narcolepsy onset [15], and also upper airway infections [16]. However, a recent study in a Spanish series of 54 narcolepsy patients only found a significant relationship with chickenpox in the year prior to narcolepsy onset, among 42 analyzed infectious factors [17]. H1N1 influenza [18] and H1N1 vaccinations [19] have also been strongly related to narcolepsy onset. It has been proposed that infectious factors could lead to an autoimmune response due to a mechanism of molecular mimicry. In summary, hypocretin neurons might become damaged in subjects with predisposing genetic factors triggered by environmental factors [20]. The autoimmune response would be acute and the symptoms of narcolepsy would appear when most neurons are damaged (more than 90\%), and this explains the absence of inflammatory signs or auto-antibodies once the condition is finally diagnosed.

Most patients suffer from the non-familial (or sporadic) form of narcolepsy, and genuine multiplex families (with several generations affected) are very rare. The disease typically begins in adolescence or early youth. The main symptom of narcolepsy is a severe and invalidating excessive daytime sleepiness (EDS), with an important impact on subject's quality of life [21]. Other symptoms are sleep paralysis (the inability to move upon awakening), hypnagogic hallucinations and a disturbed nocturnal sleep with several awakenings.

Evidence suggests that autoimmune diseases (ADs) tend to co-occur in an individual and within the same family [22], so that patients with an autoimmune disorder are at higher risk of a second $\mathrm{AD}$, and the concept of an autoimmune diathesis is now widely accepted. The association between allergic and $\mathrm{ADs}$ is also having considerable interest. ADs have been mapped to many shared loci with variable specificities to different diseases. Furthermore, recent studies have identified loci with overlapping effects on ADs and allergies. For the purpose of this study, all autoimmune and other immune-mediated disorders will be named immunopathological diseases (IDs). We have previously described an elevated prevalence of ADs and other IDs in narcolepsy with cataplexy patients [23], but no case-control studies have been made before. The aim of this retrospective study was to perform a case-control study using control subjects matched for age and gender with a series of narcolepsy type 1 (NT1) patients.

\section{Materials and Methods}

\section{Study design}

This observational retrospective case-control study was con- ducted at the Sleep Disorders Units of San Carlos University Hospital and Gregorio Maranon University Hospital in Madrid (Spain). The study was approved by the local ethic committees and a written patient's inform consent was obtained in all cases. It was divided in three parts: 1) study of an NT1 series to determine the frequency of ADs and other IDs; 2) comparison between NT1 patients with associated ADs/IDs and those without any association within the same series; 3 ) a case-control study of control subjects and narcoleptic patients from our series.

\section{Sample of NT1 patients}

A series of 158 Caucasian patients with NT1 (96 male and 62 female), with a mean age of $49.4 \pm 19.7$ years, diagnosed in our Sleep Units and taken from our respective databases, were included in the study. Although in most patients, the diagnosis of narcolepsy was made according to the previous editions of the International Classification of Sleep Disorders, all patients met the ICSD-3 (2014) criteria for NT1 and had unquestionable cataplexy. HLA typing showed that all but one patient (a familial case) were $\mathrm{DQB} 1 * 06: 02$ positive. The methodology for the assessment of the clinical and laboratory narcolepsy findings was described in our previous study, and the diagnosis was confirmed by polysomnography followed by a multiple sleep latency test, or by hypocretin-1 levels measurements [23].

The severity of the symptoms was assessed at the time of the diagnosis without treatment. To establish the severity of cataplexy, we took as a reference the Ullanlinna narcolepsy scale [24] and the parameters of the European Narcolepsy-Network (EU-NN) Retrospective Database [25]. The frequency of cataplexy was assessed by a scale from 1 to 5 , reporting rare to very frequent cataplexy attacks. We classified the patients into two groups: mild to moderate cataplexy (scores 1,2 and 3) and severe cataplexy (scores 4 and 5).

For the assessment of the ADs/IDs, patients were asked retrospectively using a comprehensive list of these diseases and symptoms. The past medical history and the medical reports from other specialists were also reviewed in all cases. The regular follow-up visits of the NT1 patients varied from 3 to 6 months. Once the presence of other ADs/IDs was confirmed, patients were systematically asked about the age at onset of the AD/ID: previous to the onset of the first symptom of narcolepsy (EDS in our series), simultaneously with EDS, or subsequent to the onset of EDS.

\section{Comparison group within the series of NT1 patients}

Thirty NT1 patients without ADs/IDs from the same series of 158 patients, matched by gender and age at onset of the first symptom (EDS), were used for comparisons with NT1 patients with comorbid ADs/IDs. All patients in this comparison group were interviewed to discard the presence of ADs or allergies at the time of this study. 
Table 1. Autoimmune and Other Immunopathological Diseases Observed in the NT1 Series $(N=158)$ and Their Prevalence in Spain*

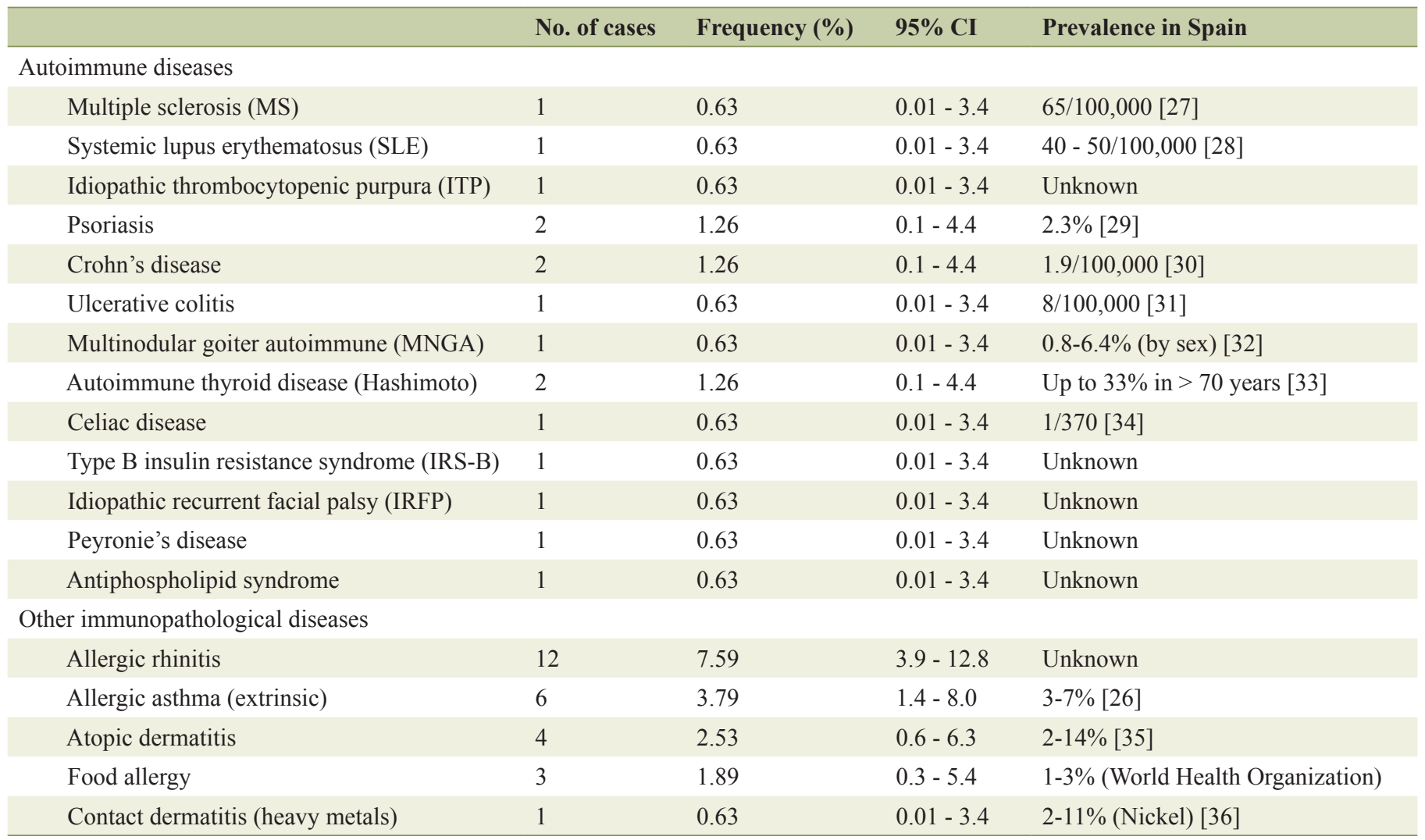

*For some of them, the prevalence observed in some European studies is accepted. Cl: confidence interval.

\section{Control group of subjects from the general population}

A control group of non-narcoleptic control and drug-free subjects were selected from the companions and non-consanguineous relatives of patients assisting to our outpatient clinics, matched by gender and age with the NT1 patients. All subjects completed a specific questionnaire with two separate sections: a sleep questionnaire, the Epworth sleepiness scale (ESS), to discard the presence of narcolepsy; and specific questions about diseases separated by organs and systems, including allergic processes. All subjects were personally interviewed by medical specialists to confirm the information. Questionnaires with uncertain or not verified diseases, presence of sleep paralysis, hypnagogic hallucinations or ESS scorings $\geq 10$, were discarded. Four hundred and thirty-four questionnaires were collected, from which 151 were finally selected. No controls could be found for seven NT1 patients due to their young or advanced age.

\section{Statistical analysis}

The Mann-Whitney and Pearson $\chi^{2}$ tests were used for the parametric comparison, and the Fisher's exact test to evaluate the severity of cataplexy. Data were reported as mean \pm SD. Dif- ferences were considered as statistically significant if $\mathrm{P}<0.05$.

\section{Results}

\section{Diseases observed in the narcolepsy series $(N=158)$}

Thirty NT1 patients out of 158 (18.99\%; 16 females, 14 males; 29 sporadic and one familial) had one or more ADs/IDs associated: $12(7.59 \%)$ had an $\mathrm{AD}, 19(12.02 \%)$ an allergic disorder, and one patient had both. Besides, seven patients had two allergic diseases at the same time, two had two ADs and one patient had three ADs. The complete listing of diseases can be seen in Table 1 [26-36]. The demographic and clinical characteristics of NT1 patients with associated ADs/IDs diseases are listed in Table 2.

One patient with NT1 and hypocretin-1 deficiency developed multiple sclerosis (MS) years later, evolving into secondary progressive MS (case 6 in Table 2). The MRI performed when MS was diagnosed showed lesions in the periventricular white matter regions but no lesions at hypothalamic sites were documented, demonstrating that the course of both diseases in this patient was independent [37]. Case 7, the first case reported in the literature with SLE and narcolepsy, was a woman in whom NT1 appeared 10 years after the SLE, and the cra- 
Table 2. Demographic and Clinical Characteristics of NT1 Patients With Associated Autoimmune and Other Immunopathological Diseases

\begin{tabular}{|c|c|c|c|c|c|c|c|c|}
\hline & Sex & $\begin{array}{l}\text { Age at } \\
\text { EDS } \\
\text { onset }\end{array}$ & ESS & $\begin{array}{l}\text { Age at } \\
\text { cataplexy } \\
\text { onset }\end{array}$ & $\begin{array}{l}\text { Frequency of } \\
\text { cataplexy (1) }\end{array}$ & $\begin{array}{l}\text { Age at } \\
\text { diagnosis } \\
\text { of NT1 }\end{array}$ & ADs/IDs & $\begin{array}{l}\text { Age at } \\
\text { diagnosis of } \\
\text { ADs/IDs }\end{array}$ \\
\hline Case 1 & $\mathrm{~F}$ & 22 & 23 & 22 & 4 & 32 & $\begin{array}{l}\text { Idiopathic recurrent facial palsy, autoimmune } \\
\text { thyroid disease, antiphospholipid syndrome }\end{array}$ & 12 \\
\hline Case 2 & $\mathrm{~F}$ & 7 & & 8 & 4 & 8 & Allergic rhinitis, food allergy & 7 \\
\hline Case 3 & M & 16 & 16 & 53 & 5 & 56 & Allergic rhinitis & 20 \\
\hline Case 5 & M & 17 & 14 & 18 & 5 & 21 & Idiopathic thrombocytopenic purpura & 17 \\
\hline Case 6 & $\mathrm{~F}$ & 12 & 15 & 12 & 4 & 27 & Multiple sclerosis & 26 \\
\hline Case 7 & $\mathrm{~F}$ & 29 & 24 & 29 & 5 & 30 & Systemic lupus erythematosus & 18 \\
\hline Case 8 & M & 19 & 15 & 21 & 4 & 22 & Psoriasis & 34 \\
\hline Case 12 & M & 39 & 17 & 39 & 5 & 42 & Allergic asthma & \\
\hline Case 13 & $\mathrm{~F}$ & 45 & 15 & 45 & 1 & 48 & Multinodular goiter autoimmune & 53 \\
\hline Case 14 & $\mathrm{~F}$ & 45 & 14 & 47 & 3 & 49 & Allergic rhinitis & 18 \\
\hline Case 15 & M & 12 & 19 & 25 & 4 & 19 & Psoriasis & 10 \\
\hline Case 16 & $\mathrm{~F}$ & 9 & 17 & 9 & 5 & 28 & Crohn's disease, allergic rhinitis & 9 \\
\hline Case 17 & M & 20 & 19 & 22 & 4 & 26 & Allergic rhinitis & 9 \\
\hline Case 18 & $\mathrm{~F}$ & 10 & 21 & 10 & 5 & 20 & Allergic rhinitis & 10 \\
\hline Case 19 & $\mathrm{~F}$ & 23 & & 26 & 5 & & Allergic rhinitis, contact dermatitis (heavy metals) & 14 \\
\hline Case 20 & M & 25 & 22 & 23 & 4 & 34 & Allergic asthma & 15 \\
\hline Case 27 & $\mathrm{~F}$ & 7 & 19 & 11 & 5 & 9 & Type B insulin resistance syndrome (IRS-B) & 15 \\
\hline Case 28 & $\mathrm{~F}$ & 19 & 17 & 20 & 5 & 25 & Crohn's disease, celiac disease & 20 \\
\hline Case 29 & $\mathrm{~F}$ & 16 & 19 & 18 & 4 & 18 & Allergic rhinitis & 15 \\
\hline Case 30 & M & 14 & 20 & 18 & 5 & 67 & Atopic dermatitis & 22 \\
\hline
\end{tabular}

nial MRI was normal [38]. The familial case (case 5), suffering from extreme obesity, belongs to the largest ever-reported narcolepsy family with 12 affected members. The patient was diagnosed with idiopathic thrombocytopenic purpura (ITP) at the age of 18; EDS and cataplectic attacks started at the same age. The ITP was initially successfully treated with corticoids, and a myelin oligodendrocyte glycoprotein (MOG) mutation was identified in this family [39].

Hypocretin-1 level in cerebrospinal fluid (CSF) was determined in two patients (cases 6 and 10), and was undetectable in both cases. In case 10, the level of hypocretin-1 in CSF re- mained undetectable after 6 months of treatment with intravenous immunoglobulins [40].

\section{Comparative analysis of the NT1 group with ADs/IDs and the NT1 group without ADs/IDs}

The results of the statistical analysis are reported in Table 3. Cataplexy was significantly more severe in the group of NT1 patients with IDs $(\mathrm{P}<0.001)$ (Table 4). The univariate analysis of both groups of patients revealed that the presence of ADs/ 
Table 3. Results of the Comparative Analysis of the Group of NT1 Patients With ADs/IDs and the Group of NT1 Patients Without ADs/IDs $(\mathrm{N}=30)$

\begin{tabular}{|c|c|c|c|}
\hline & NT1, mean \pm SD & NT1 + ADs/IDs, mean \pm SD & P (Mann-Whitney) \\
\hline Age & $49.6 \pm 20.6($ median: $45 ;$ IR: $33-68)$ & $38 \pm 18.3($ median: $36 ;$ IR: $28-43)$ & 0.071 \\
\hline Sex & 16 female $(53.3 \%) ; 14$ male $(46.7 \%)$ & & $0.067^{*}$ \\
\hline Epworth sleepiness scale (ESS) & $19.1 \pm 2.5$ (median: $19 ;$ IR: $18-20)$ & $17.6 \pm 3.3$ (median: $17 ;$ IR: $15-20)$ & 0.043 \\
\hline Age at EDS onset & $19.6 \pm 9.5$ (median: 18; IR: 14 - 24) & $19.2 \pm 9.9$ (median: 17.5; IR: 12 - 23) & 0.926 \\
\hline $\begin{array}{l}\text { Hypnagogic hallucinations (no. } \\
\text { of cases and } \% \text { patients) }\end{array}$ & $15(50.0 \%)$ & $17(56.7 \%)$ & $0.267^{*}$ \\
\hline $\begin{array}{l}\text { Sleep paralysis (no. of cases } \\
\text { and \% patients) }\end{array}$ & $20(66.6 \%)$ & $17(56.6 \%)$ & $0.634 *$ \\
\hline
\end{tabular}

${ }^{*}$ Pearson $\mathrm{X}^{2}$ test. BMI: body mass index; IR: interquartile range (p25 - p75).

IDs in NT1 is an important risk factor for severe forms of cataplexy in our series (OR: 23.6). It has been previously described that close-to-onset cases have more severe symptoms, especially for cataplexy, and the age also seems to be a determinant factor in our series: patients with severe cataplexy are younger, and an advanced age is a mild protective factor (OR: 0.95), as well as an older age onset for cataplexy (OR: 0.94) (Table 5).

\section{Diseases observed in the control group of general popula- tion}

A total number of 151 matched controls were selected for this group. Eighteen controls (11.92\%) had IDs: four $(2.64 \%)$ had ADs and 16 (10.59\%) had allergic diseases. Besides, two had one of each type, one subject had two allergic diseases, and none had two or more ADs. All the observed diseases are listed in Table 6.

The comparative analysis of these two groups (as shown in Table 7) reveals that ADs/IDs in general are more frequent in NT1 (19.2\% vs. $11.9 \%$ in controls; OR: $1.75 ; 95 \%$ CI: 0.92 - 3.32 ), as well as allergic diseases (12.5\% vs. $10.6 \%$; OR: 1.21 ; $95 \%$ CI: $0.59-2.46)$, but the difference is not significant, whereas ADs are significantly more frequent in NT1 (7.9\% vs. 2.6\%; OR: 3.17; 95\% CI: 1.01 - 10.07).

\section{Discussion}

The results from the comparative analysis of narcolepsy patients and the control group lead to a first conclusion: there is a higher frequency of ADs in NT1 than in controls $(7.95 \%$ in
NT1 vs. $2.65 \%$ in controls; OR: 3.17 ), which strengthens the idea that narcolepsy has an autoimmune pathogenesis. The association with other allergic diseases is also high, although the difference was not statistically significant mainly due to the high prevalence of allergic rhinitis in our environment.

Several population-based studies have demonstrated positive associations between different ADs, allergic diseases, and even between both types. ADs have been traditionally considered as separate entities, but the concept of shared autoimmunity is gaining acceptance. There is also the concept of familial aggregation, multiple autoimmune syndrome, and mosaic of autoimmunity [41-43]. Although many ADs are individually rare, Jacobson et al estimated that together affect one in every 31 US citizens [44], representing $3.22 \%$ of the population. The sample of subjects from the general population obtained for this study, with an $\mathrm{AD}$ prevalence of $3.45 \%$, could then be considered quite representative. But the first study of prevalence with a complete list of ADs was published in 2012 by Hayter and Cook [45]. This study established an AD overall prevalence of $2.7 \%$ for men and $6.4 \%$ for women. The study included narcolepsy for the first time, and established the periods of highest incidence for different ADs, being highest for narcolepsy in the second decade of life (10 - 19 years). The peak incidence of ADs as a whole occurred during the third (20 - 29 years) but, above all, in the fifth decade of life (40 - 49 years). In the present study, eight of the 12 patients with associated ADs (two-thirds) reported the first symptom of narcolepsy (EDS) before the age of 20, two of whom were before 10 years. Taking as a reference all the IDs observed in this group, we can include 20 of the 30 patients (the same proportion, twothirds), four before 10 years of age. This indicates that patients with NT1 and IDs (not only ADs) tend to manifest narcolepsy

Table 4. Comparative Analysis of the Severity of Cataplexy Between the Group of NT1 Patients With ADs/IDs and the Group of NT1 Patients Without ADs/IDs (N=30)

\begin{tabular}{llll}
\hline Severity of cataplexy* & NT1, No. (\%) & NT1 + IDs, No. (\%) & P \\
\hline Mild to moderate $(1,2,3)$ & $21(72.4 \%)$ & $3(10 \%)$ & $<0.001$ \\
Severe $(4,5)$ & $8(27.6 \%)$ & $27(90 \%)$ & \\
\hline
\end{tabular}

${ }^{*}$ EU-NN: $1:<1 /$ year; $2:<1 /$ month; $3:<1 /$ week; 4: < 1/day; 5: > 1/day. 
Table 5. Univariate Analysis of Factors Related to the Severity of Cataplexy in the 30 NT1 Patients With ADs/IDs and the 30 NT1 Patients Without ADs/IDs ( $=60)$

\begin{tabular}{|c|c|c|c|c|}
\hline Severity of cataplexy* & Mild to moderate $(1,2,3)$ & Severe $(4,5)$ & OR & 95\% CI for OR \\
\hline Sex & & & 1.12 & $0.39-3.20$ \\
\hline Male & $42.3 \%$ & $57.7 \%$ & & \\
\hline Female & $39.4 \%$ & $60.6 \%$ & & \\
\hline Age (years) & $53.5 \pm 20.2$ & $37.1 \pm 17.9$ & 0.95 & $0.92-0.98$ \\
\hline Presence of IDs & & & 23.6 & $5.5-100.1$ \\
\hline No & $72.4 \%$ & $27.6 \%$ & & \\
\hline Yes & $10 \%$ & $90 \%$ & & \\
\hline Epworth (ESS) & $18.4 \pm 2.5$ & $18.2 \pm 3.4$ & 0.98 & $0.82-1.17$ \\
\hline Age at cataplexy onset (years) & $28 \pm 16.3$ & $19.2 \pm 9.3$ & 0.94 & $0.90-0.99$ \\
\hline
\end{tabular}

*EU-NN: 1: < 1/year; 2: < 1/month; 3: <1/week; 4: < 1/day; 5: > 1/day. OR: odds ratio; Cl: confidence interval.

earlier. This finding is important because studies that have analyzed age ranges with the highest incidence of narcolepsy have not taken into account the coexistence of other ADs/IDs, which could be a determining factor.

A recent study in 468 narcolepsy pediatric patients also found an increased frequency of allergic conditions, which was higher in patients with cataplexy compared to those without cataplexy. The study hypothesizes that Th2 cellular hyperactivation against autoantigens would cause IgE-mediated allergy and hypersensitivity [46]. The presence of allergic conditions may modulate the severity of the disease in childhood narcolepsy, and reduce the prevalence of cataplexy in these patients. The study, however, does not evaluate the presence of ADs, and the discrepancies with our study observed in the severity of cataplexy could be explained because we only included NT1 in our study. The most important marker for cataplexy - the allele DQB1*06:02 - varies in percentage in different ethnic populations (Caucasian, Asiatic and Amerindian). Also the environmental factors, as a trigger for narcolepsy, are different in children from three continents.

Regarding gender differences for ADs, women bear the greatest burden: the previously published studies established that women have 2.7 times more risk than men to acquire one [47]. For Hayter and Cook, 47 ADs (58\%) are more common in women and only 21 have a marked female predominance (75$100 \%$ ). The cause of this increased risk in women is unknown. In the present study, the sample of 158 patients with NT1 is predominantly male $(60.7 \%)$. However, the trend is clearly reversed in the sample of 30 patients with associated ADs, with a female predominance $(66.6 \%)$. This means that $12.9 \%$ women in this sample of 158 patients with NT1 have at least one AD, compared with only $4.1 \%$ men. It is well known that there is no gender predominance in narcolepsy, and our results support the classical hypothesis of a higher susceptibility in females to develop other ADs (e.g. autoimmune thyroid disease). It is widely believed that there are approximately $80 \mathrm{ADs}$, according to Witebsky's postulates [48]. The ADs detected in our series are a heterogeneous group and they all meet, if not all, at least two of these postulates. Most of them have a universally accepted autoimmune pathophysiology, but others have not been included so far in the published series, namely, Peyronie's disease, multinodular goiter autoimmune, type B insulin resistance syndrome and idiopathic recurrent facial palsy.

The other ADs observed in this sample of patients with

Table 6. Autoimmune and Other Immunopathological Diseases Observed in the Control Group of General Population $(\mathrm{N}=151)$

\begin{tabular}{llll}
\hline & Number of cases & Frequency (\%) & $\mathbf{9 5 \%}$ CI \\
\hline $\begin{array}{l}\text { Autoimmune diseases } \\
\quad \text { Psoriasis }\end{array}$ & 1 & & $0.01-3.6$ \\
$\quad$ Ulcerative colitis & 1 & 0.66 & $0.01-3.6$ \\
$\quad$ Autoimmune thyroid disease (Hashimoto) & 2 & 0.66 & $0.02-4.7$ \\
Other immunopathological diseases & 12 & 1.32 & $4.1-13.4$ \\
$\quad$ Allergic rhinitis & 2 & 7.94 & $0.02-4.7$ \\
Allergic asthma (extrinsic) & 2 & 1.32 & $0.02-4.7$ \\
Atopic dermatitis & 1 & 1.32 & $0.01-3.6$ \\
\hline Food allergy & & 0.66 & \\
\hline
\end{tabular}

$\mathrm{Cl}$ : confidence interval. 
Table 7. Comparative Analysis Between the Group of NT1 Patients and the Control Group of General Population (N = 151)

\begin{tabular}{lllllll}
\hline & NT1 patients, No. $(\%)$ & Controls, No. $(\%)$ & P (Pearson $\left.\chi^{\mathbf{2}}\right)$ & RR & OR & 95\% CI for OR \\
\hline ADs & $12(7.95 \%)$ & $4(2.65 \%)$ & 0.040 & 3.00 & 3.17 & $1.01-10.07$ \\
Other IDs & $19(12.58 \%)$ & $16(10.60 \%)$ & 0.590 & 1.19 & 1.21 & $0.59-2.46$ \\
All & $29(19.21 \%)$ & $18(11.92 \%)$ & 0.081 & 1.61 & 1.75 & $0.92-3.32$ \\
\hline
\end{tabular}

RR: relative risk; OR: odds ratio; $\mathrm{Cl}$ : confidence interval.

NT1 have, as already mentioned, a generally accepted autoimmune origin, and MS is of particular interest in this study. Although the etiology of MS remains unknown, it is thought that a combination of genetic and environmental factors is involved, as well as in narcolepsy. But both diseases also share other similarities. The first cases of MS and narcolepsy were described by Ekbom in 1966 [49]. It is also known that MS and narcolepsy share genes conferring susceptibility [5]. HLAclass II of both diseases share the DRB1*15:01-DQB1*06:02 haplotype [50-52]. Recently, a mutation in the MOG gene has been detected in the largest narcoleptic family ever described, with 12 members affected by the disease, and it was not observed in the healthy members of the same family [39]. Case 6 (Table 2) is a member of this family, and the only DQB1*06:02 negative patient in our series. The identification of the MOG gene mutation, exclusive of this Spanish family, provides a better understanding of the pathogenesis of narcolepsy and highlights the role of a glycoprotein believed to be important in the myelination of nerves in the central nervous system, and further emphasizes glial involvement in neurodegeneration and neurobehavioral disorders.

In celiac disease (case 28), associations with other ADs have been identified before, including type 1 diabetes mellitus (DM), autoimmune thyroiditis, SLE and Crohn's disease (CrD) [53] (as in this patient), but never before with narcolepsy. $\mathrm{CrD}$ is also present in case 16 , another woman who debuted with the first signs of NT1 at the age of 9 years, immediately after a first outbreak of allergic rhinitis. No cases of comorbidity between $\mathrm{CrD}$ and NT1 have been reported before, but a study in Tunisia, another Mediterranean country, showed a high prevalence of the DRB1*15:01 allele [54]. Ulcerative colitis (UC) was observed in case 25 of this sample. UC etiology involves, as in $\mathrm{CrD}$, genetic and environmental factors, and a study in Spain showed a high frequency of DR2 [55]. In children, UC has been associated with an increased risk for type 1 DM and an increased frequency of asthma, allergic rhinitis, autoimmune hypothyroidism, rheumatoid arthritis and SLE [56].

The secondary form of antiphospholipid syndrome occurs in the context of ADs such as SLE. Another AD observed in this series is ITP, a rare disease. No associations have been described between ITP and narcolepsy before. The case presented in this series is a 31-year-old man who was diagnosed with ITP at the age of 17, manifesting EDS at the same age. In this case there is a temporal relationship in the beginning of both diseases that may have conditioned their development and evolution. Several studies have found a higher frequency of psoriasis in patients with MS [57]. Associations between psoriasis and other ADs, like SLE or autoimmune hypothyroidism, have also been reported, but never before with NT1.
Regarding other IDs described in this sample of patients with NT1, they can be described collectively as allergic diseases. They share some common characteristics: a high prevalence among the population and a marked genetic/hereditary component in most of them. This is the case of allergic rhinitis, allergic asthma, atopic dermatitis, food allergies and contact dermatitis. A study in Spain [26] over adolescents aged 13 14 years showed that $9.4 \%$ had allergic rhinitis, and $10.3 \%$ had atopic dermatitis. The interaction between allergic rhinitis, asthma and atopic dermatitis is well known [58], suggesting that the disease has a multifactorial etiology in which common genetic and environmental factors are involved. Regarding the HLA system in asthma, the most frequently associated haplotype in Spanish population is DRB1*01 [59]. In contact dermatitis, various loci conferring susceptibility to nickel dermatitis have been described [60].

Recent studies show that the prevalence of food allergies is increasing. Again, genetic factors play an important role. A strong association between the HLA-DR15-DQB1*06:02 and allergy to cow's milk has been described [61], which is present in a patient of the study sample (case 10). Our series include the case of a child with NT1 who developed the disease at an early age (6 years) after oral immunotherapy to cow milk [40]. It has also been described an increased frequency of HLADRB1*15:01 in patients with atopic dermatitis and egg allergy than those who do not have the latter [62].

In summary, it seems clear that genetics play an important role in the ADs/IDs found in this sample of NT1 patients. The comorbidity with narcolepsy in some of our cases is not a coincidence, as they even share some alleles conferring susceptibility. Cross-associations between them are, as shown, very frequent, such as celiac disease/SLE and SLE/narcolepsy, or between psoriasis/MS and MS/narcolepsy, suggesting that they share certain genetic characteristics that confer increased susceptibility. It has also been reported that MS patients have a greater risk for other ADs compared to the general population $[63,64]$. Using MS and narcolepsy as an example, it is clear that the susceptibility to these diseases results from interaction of genes, environment and gene/environment. The prevalence of ADs/IDs is high in this series (18.98\%), suggesting that narcolepsy might arise on a background of generalized susceptibility to immune-mediated processes.

A recent study over 3,000 cases of European and Chinese background [65] has found new associations with HLA-DP alleles, but also in the HLA-class I region, suggesting an independent role for these HLA alleles similar to other ADs. Another study in 944 European NT1 patients [66] has also found HLA-class I alleles associated with susceptibility to narcolepsy, providing a genetic basis for increased susceptibility 
to infectious factors or an immune cytotoxic mechanism, potentially targeting hypocretin neurons. As explained by Degn and Kornum [67], narcolepsy is closely linked to HLA-class II molecules, suggesting that $\mathrm{CD} 4^{+} \mathrm{T}$ cells play an important role in these diseases. However, $\mathrm{CD}^{+} \mathrm{T}$ cells are not cytotoxic in general, and HLA-class II molecules have never been detected on neurons in contrast to HLA-class I. This supports the idea that cytotoxic $\mathrm{CD} 8^{+} \mathrm{T}$ cells could play a central role: they recognize antigens presented by HLA-class I molecules to damage a cell. Furthermore, HLA-I expression is absent or very low on mature brain neurons, but they can upregulate and express HLA-I in response to immune stimuli.

Our findings support this hypothesis. We speculate that the occurrence of an immunopathological disease can in turn influence the development of others in genetically predisposed individuals, which explains some of the temporary associations observed in this study. This was already proposed by Salemi and D'Amelio [68], who suggested that a generalized stimulation of the immune system motivated by a vaccine might secondarily cause autoimmune responses. The child included in this study with NT1 after oral immunotherapy to cow milk is an excellent example to illustrate this mechanism. Besides, the analysis of the temporal relationship between the EDS onset and the presentation of the ADs/IDs showed that in 15 cases $(50 \%)$ the diagnosis of the $\mathrm{AD} / \mathrm{ID}$ preceded the $\mathrm{EDS}$, and in four cases (13.3\%) both EDS and $\mathrm{AD} / \mathrm{ID}$ appeared simultaneously (e.g., immediately after the first allergic event in three cases). This indicates that immune-mediated responses could have acted as a trigger for narcolepsy in a majority of patients. In these patients in whom the $\mathrm{AD} / \mathrm{ID}$ precedes or is simultaneous to narcolepsy (19 in total), an early age at onset of the AD/ID usually correlates with an early age at onset of NT1 (see cases 2, 10, 15, 16 and 18 in Table 2), suggesting again a mechanism of modulation or activation by the ADs/IDs. None of these patients were treated with antidepressants or stimulants at the time of diagnosis of the $\mathrm{ADs} / \mathrm{ID}$. In the remaining 11 cases $(36.6 \%)$, the ADs/ID starts after NT1. All of them were then treated with stimulants and five also with antidepressants, an aspect that has to be taken into account due to its possible immunomodulatory effect. If we analyze individually the age at onset of the ADs in this sample of NT1 patients, and compare them with those described by Hayter and Cook, it can be concluded that they do not appear before than expected.

This study has some limitations: it is retrospective, and a recall bias can exist. But it initiates a work line for others to come. There have been some attempts in the recent past to stop the immune response that might cause narcolepsy [69]. Further studies will be necessary to identify clinical and genetic associations between narcolepsy and ADs/IDs and, perhaps, it would allow detecting the more severe cases in the early stages of the disease, providing an opportunity for immune-modulating therapies. The controls were not HLA-DQB1*06:02 matched to the cases.

\section{Acknowledgments}

The authors are thankful to the patients and controls subjects' participants in the study. We are grateful to Prof. MatiasGuiu, co-advisor of the $\mathrm{PhD}$ doctoral thesis.

\section{Previous Presentation}

This study was presented as a $\mathrm{PhD}$ doctoral thesis by Francisco-Javier Martinez-Orozco at the Complutense University of Madrid (April 2015).

\section{Conflicts of Interest}

None of the authors has any potential financial conflict of interest related to this manuscript.

\section{Author Contributions}

Dr. Francisco-Javier Martinez-Orozco, Dr. Rosa Peraita-Adrados and Dr. Clara De Andres have seen the patients at their outpatient clinics, conducted all the clinical workup and revised the manuscript for intellectual content. Dr. Jose L. Vicario and Dr. Miguel Fernandez-Arquero have performed the HLA analysis and revised the manuscript for intellectual content. Dr. Francisco-Javier Martinez-Orozco and Dr. Rosa PeraitaAdrados have drafted the original manuscript.

\section{References}

1. Longstreth WT, Jr., Koepsell TD, Ton TG, Hendrickson AF, van Belle G. The epidemiology of narcolepsy. Sleep. 2007;30(1):13-26.

2. Ohayon MM, Priest RG, Zulley J, Smirne S, Paiva T. Prevalence of narcolepsy symptomatology and diagnosis in the European general population. Neurology. 2002;58(12):1826-1833.

3. de Lecea L, Kilduff TS, Peyron C, Gao X, Foye PE, Danielson PE, Fukuhara C, et al. The hypocretins: hypothalamus-specific peptides with neuroexcitatory activity. Proc Natl Acad Sci U S A. 1998;95(1):322-327.

4. Nishino S, Ripley B, Overeem S, Lammers GJ, Mignot E. Hypocretin (orexin) deficiency in human narcolepsy. Lancet. 2000;355(9197):39-40.

5. Katzav A, Arango MT, Kivity S, Tanaka S, Givaty G, Agmon-Levin N, Honda M, et al. Passive transfer of narcolepsy: anti-TRIB2 autoantibody positive patient IgG causes hypothalamic orexin neuron loss and sleep attacks in mice. J Autoimmun. 2013;45:24-30.

6. Bergman P, Adori C, Vas S, Kai-Larsen Y, Sarkanen T, Cederlund A, Agerberth B, et al. Narcolepsy patients have antibodies that stain distinct cell populations in rat brain and influence sleep patterns. Proc Natl Acad Sci U S A. 2014;111(35):E3735-3744.

7. Smith AJ, Jackson MW, Neufing P, McEvoy RD, Gordon TP. A functional autoantibody in narcolepsy. Lancet. 2004;364(9451):2122-2124. 
8. Juji T, Satake M, Honda Y, Doi Y. HLA antigens in Japanese patients with narcolepsy. All the patients were DR2 positive. Tissue Antigens. 1984;24(5):316-319.

9. Mignot E, Lin X, Arrigoni J, Macaubas C, Olive F, Hallmayer J, Underhill P, et al. DQB $1 * 0602$ and DQA $1 * 0102$ (DQ1) are better markers than DR2 for narcolepsy in Caucasian and black Americans. Sleep. 1994;17(8 Suppl):S60-67.

10. Tafti M, Hor H, Dauvilliers Y, Lammers GJ, Overeem S, Mayer G, Javidi S, et al. DQB1 locus alone explains most of the risk and protection in narcolepsy with cataplexy in Europe. Sleep. 2014;37(1):19-25.

11. Peraita-Adrados R, Ezpeleta D, Balas A, MarinezJaso J,Vicario JL. Frequencies of allelic associations DQQB1*0602 with DQB1*0301 and other HLA-subtypes in a 40 narcolepsy-cataplexy case series. J Sleep Res. 2000;9(suppl. 1):S150.

12. Hallmayer J, Faraco J, Lin L, Hesselson S, Winkelmann J, Kawashima M, Mayer G, et al. Narcolepsy is strongly associated with the T-cell receptor alpha locus. Nat Genet. 2009;41(6):708-711.

13. Cvetkovic-Lopes V, Bayer L, Dorsaz S, Maret S, Pradervand S, Dauvilliers Y, Lecendreux M, et al. Elevated Tribbles homolog 2-specific antibody levels in narcolepsy patients. J Clin Invest. 2010;120(3):713-719.

14. Dauvilliers Y, Montplaisir J, Cochen V, Desautels A, Einen M, Lin L, Kawashima M, et al. Post-H1N1 narcolepsycataplexy. Sleep. 2010;33(11):1428-1430.

15. Aran A, Lin L, Nevsimalova S, Plazzi G, Hong SC, Weiner K, Zeitzer J, et al. Elevated anti-streptococcal antibodies in patients with recent narcolepsy onset. Sleep. 2009;32(8):979-983.

16. Koepsell TD, Longstreth WT, Ton TG. Medical exposures in youth and the frequency of narcolepsy with cataplexy: a population-based case-control study in genetically predisposed people. J Sleep Res. 2010;19(1 Pt 1):80-86.

17. Peraita-Adrados R, del Rio-Villegas R, Vela-Bueno A. Environmental factors in the development of narcolepsy with cataplexy. A case-control study. Rev Neurol. 2015;60(12):529-534.

18. Han F, Lin L, Warby SC, Faraco J, Li J, Dong SX, An $P$, et al. Narcolepsy onset is seasonal and increased following the 2009 H1N1 pandemic in China. Ann Neurol. 2011;70(3):410-417.

19. Nohynek H, Jokinen J, Partinen M, Vaarala O, Kirjavainen T, Sundman J, Himanen SL, et al. AS03 adjuvanted AH1N1 vaccine associated with an abrupt increase in the incidence of childhood narcolepsy in Finland. PLoS One. 2012;7(3):e33536.

20. Arango MT, Kivity S, Chapman J, Shoenfeld Y. Narcolepsy - genes, infections and vaccines: the clues for a new autoimmune disease. Isr Med Assoc J. 2014;16(10):636637.

21. Jennum P, Ibsen R, Petersen ER, Knudsen S, Kjellberg J. Health, social, and economic consequences of narcolepsy: a controlled national study evaluating the societal effect on patients and their partners. Sleep Med. 2012;13(8):1086-1093.

22. Somers EC, Thomas SL, Smeeth L, Hall AJ. Autoimmune diseases co-occurring within individuals and within families: a systematic review. Epidemiology. 2006;17(2):202217.

23. Martinez-Orozco FJ, Vicario JL, Villalibre-Valderrey I, De Andres C, Fernandez-Arquero M, Peraita-Adrados R. Narcolepsy with cataplexy and comorbid immunopathological diseases. J Sleep Res. 2014;23(4):414-419.

24. Hublin C, Kaprio J, Partinen M, Koskenvuo M, Heikkila K. The Ullanlinna Narcolepsy Scale: validation of a measure of symptoms in the narcoleptic syndrome. J Sleep Res. 1994;3(1):52-59.

25. Luca G, Haba-Rubio J, Dauvilliers Y, Lammers GJ, Overeem S, Donjacour CE, Mayer G, et al. Clinical, polysomnographic and genome-wide association analyses of narcolepsy with cataplexy: a European Narcolepsy Network study. J Sleep Res. 2013;22(5):482-495.

26. [Prevalence of symptoms suggestive of allergic rhinitis and atopic dermatitis in adolescents (Spanish ISAAC Study Group)]. An Esp Pediatr. 1999;51(4):369-376.

27. Bartulos Iglesias M, Marzo Sola ME, Estrella Ruiz LA, Bravo Anguiano Y. Epidemiological study of multiple sclerosis in La Rioja. Neurologia. 2015;30(9):552-560.

28. Cervera R, Doria A, Amoura Z, Khamashta M, Schneider M, Guillemin F, Maurel F, et al. Patterns of systemic lupus erythematosus expression in Europe. Autoimmun Rev. 2014;13(6):621-629.

29. Ferrandiz C, Carrascosa JM, Toro M. Prevalence of psoriasis in Spain in the age of biologics. Actas Dermosifiliogr. 2014;105(5):504-509.

30. Lopez-Serrano P, Perez-Calle JL, Carrera-Alonso E, Perez-Fernandez T, Rodriguez-Caravaca G, Boixedade-Miguel D, Fernandez-Rodriguez CM. Epidemiologic study on the current incidence of inflammatory bowel disease in Madrid. Rev Esp Enferm Dig. 2009;101(11):768772.

31. Lopez-Serrano P, Perez-Calle JL, Fernandez-Rodriguez C. Ulcerative colitis in Madrid, Spain: current management. Inflamm Bowel Dis. 2010;16(11):1826-1827.

32. Corrales JJ, Orfao A, Miralles JM, Lopez-Berges MC, Garcia LC, Gonzalez M, Mories MT, et al. Immunological features of sporadic multinodular goiter. Clin Investig. 1993;71(7):552-558.

33. McGrogan A, Seaman HE, Wright JW, de Vries CS. The incidence of autoimmune thyroid disease: a systematic review of the literature. Clin Endocrinol (Oxf). 2008;69(5):687-696.

34. Garcia Novo MD, Garfia C, Acuna Quiros MD, Asensio J, Zancada G, Barrio Gutierrez S, Manzanares J, et al. [Prevalence of celiac disease in apparently healthy blood donors in the autonomous community of Madrid]. Rev Esp Enferm Dig. 2007;99(6):337-342.

35. Lugovic L, Lipozencic J. Are respiratory allergic diseases related to atopic dermatitis? Coll Antropol. 2000;24(2):335-345.

36. Friedmann PS, Pickard C. Contact hypersensitivity: quantitative aspects, susceptibility and risk factors. EXS. 2014;104:51-71.

37. Peraita-Adrados R, Lammers GJ, De Andres C, Santamaria J, Vicario JL, Tafti M. A patient with narcolepsy with 
cataplexy and multiple sclerosis: two different diseases that may share pathophysiologic mechanisms? Sleep Med. 2013;14(7):695-696.

38. Pablos JL, del Rincon E, Francisco F, Mateo I. Narcolepsy in systemic lupus erythematosus. J Rheumatol. 1993;20(2):375-376.

39. Hor H, Bartesaghi L, Kutalik Z, Vicario JL, de Andres C, Pfister C, Lammers GJ, et al. A missense mutation in myelin oligodendrocyte glycoprotein as a cause of familial narcolepsy with cataplexy. Am J Hum Genet. 2011;89(3):474-479.

40. Peraita-Adrados R, Lopez-Esteban P, Garcia-Penas JJ, Vicario JL, Escudero C, Santamaria J, Casamitjana R, et al. Narcolepsy-cataplexy induced by a cow milk oral immunotherapy protocol? Sleep Med. 2011;12(7):730-731.

41. Castiblanco J, Sarmiento-Monroy JC, Mantilla RD, Rojas-Villarraga A, Anaya JM. Familial Aggregation and Segregation Analysis in Families Presenting Autoimmunity, Polyautoimmunity, and Multiple Autoimmune Syndrome. J Immunol Res. 2015;2015:572353.

42. Cardenas-Roldan J, Rojas-Villarraga A, Anaya JM. How do autoimmune diseases cluster in families? A systematic review and meta-analysis. BMC Med. 2013;11:73.

43. Anaya JM. Common mechanisms of autoimmune diseases (the autoimmune tautology). Autoimmun Rev. 2012;11(11):781-784.

44. Jacobson DL, Gange SJ, Rose NR, Graham NM. Epidemiology and estimated population burden of selected autoimmune diseases in the United States. Clin Immunol Immunopathol. 1997;84(3):223-243.

45. Hayter SM, Cook MC. Updated assessment of the prevalence, spectrum and case definition of autoimmune disease. Autoimmun Rev. 2012;11(10):754-765.

46. Aydinoz S, Huang YS, Gozal D, Inocente CO, Franco P, Kheirandish-Gozal L. Allergies and Disease Severity in Childhood Narcolepsy: Preliminary Findings. Sleep. 2015;38(12):1981-1984.

47. National Institutes of Health. Autoimmune Diseases Coordinating Committee: Autoimmune Diseases Research Plan. National Institutes of Health. 2005.

48. Rose NR, Bona C. Defining criteria for autoimmune diseases (Witebsky's postulates revisited). Immunol Today. 1993;14(9):426-430.

49. Ekbom K. Familial multiple sclerosis associated with narcolepsy. Arch Neurol. 1966;15(4):337-344.

50. Younger DS, Pedley TA, Thorpy MJ. Multiple sclerosis and narcolepsy: possible similar genetic susceptibility. Neurology. 1991;41(3):447-448.

51. Fogdell A, Hillert J, Sachs C, Olerup O. The multiple sclerosis- and narcolepsy-associated HLA class II haplotype includes the DRB5*0101 allele. Tissue Antigens. 1995;46(4):333-336.

52. Dyment DA, Ebers GC, Sadovnick AD. Genetics of multiple sclerosis. Lancet Neurol. 2004;3(2):104-110.

53. Ciobanu L, Pascu O, Iobagiu S, Damian D, Dumitru E, Tantau M. Unknown complicated celiac disease as an unexpected finding in patients investigated with capsule endoscopy for Crohn's disease. A case series. J Gastrointestin Liver Dis. 2013;22(1):97-100.
54. Bouzid D, Kammoun A, Amouri A, Mahfoudh N, Haddouk S, Tahri N, Makni H, et al. Inflammatory bowel disease: susceptibility and disease heterogeneity revealed by human leukocyte antigen genotyping. Genet Test Mol Biomarkers. 2012;16(6):482-487.

55. Garcia Herola A, Nos P, Hinijosa J, Hoyos M, Moles JR, Carmona E, Puig N, et al. HLA antigens and anti-neutrophil cytoplasmic antibodies (ANCA) in inflammatory bowel disease. Rev Esp Enferm Dig. 2003;95(11):760764, 755-769.

56. Kappelman MD, Galanko JA, Porter CQ, Sandler RS. Association of paediatric inflammatory bowel disease with other immune-mediated diseases. Arch Dis Child. 2011;96(11):1042-1046.

57. Fellner A, Dano M, Regev K, Mosek A, Karni A. Multiple sclerosis is associated with psoriasis. A case-control study. J Neurol Sci. 2014;338(1-2):226-228.

58. Dold S, Wjst M, von Mutius E, Reitmeir P, Stiepel E. Genetic risk for asthma, allergic rhinitis, and atopic dermatitis. Arch Dis Child. 1992;67(8):1018-1022.

59. Torio A, Sanchez-Guerrero I, Muro M, Villar LM, Minguela A, Marin L, Moya-Quiles MR, et al. HLA class II genotypic frequencies in atopic asthma: association of DRB1*01-DQB $1 * 0501$ genotype with Artemisia vulgaris allergic asthma. Hum Immunol. 2003;64(8):811815.

60. Kim DS, Kim DH, Lee H, Jee H, Lee Y, Chang MY, Kwak TJ, et al. A genome-wide association study in Koreans identifies susceptibility loci for allergic nickel dermatitis. Int Arch Allergy Immunol. 2013;162(2):184-186.

61. Savilahti EM, Ilonen J, Kiviniemi M, Saarinen KM, Vaarala O, Savilahti E. Human leukocyte antigen (DR1)DQB $1 * 0501$ and (DR15)-DQB1*0602 haplotypes are associated with humoral responses to early food allergens in children. Int Arch Allergy Immunol. 2010;152(2):169177.

62. Park H, Ahn K, Park MH, Lee SI. The HLA-DRB1 Polymorphism is Associated With Atopic Dermatitis, but not Egg Allergy in Korean Children. Allergy Asthma Immunol Res. 2012;4(3):143-149.

63. Henderson RD, Bain CJ, Pender MP. The occurrence of autoimmune diseases in patients with multiple sclerosis and their families. J Clin Neurosci. 2000;7(5):434-437.

64. Barcellos LF, Kamdar BB, Ramsay PP, DeLoa C, Lincoln RR, Caillier S, Schmidt S, et al. Clustering of autoimmune diseases in families with a high-risk for multiple sclerosis: a descriptive study. Lancet Neurol. 2006;5(11):924931.

65. Ollila HM, Ravel JM, Han F, Faraco J, Lin L, Zheng X, Plazzi G, et al. HLA-DPB1 and HLA class I confer risk of and protection from narcolepsy. Am J Hum Genet. 2015;96(1):136-146.

66. Tafti M, Lammers GJ, Dauvilliers Y, Overeem S, Mayer G, Nowak J, Pfister C, et al. Narcolepsy-Associated HLA Class I Alleles Implicate Cell-Mediated Cytotoxicity. Sleep. 2016;39(3):581-587.

67. Degn M, Kornum BR. Type 1 narcolepsy: a CD8(+) T cell-mediated disease? Ann N Y Acad Sci. 2015;1351:8088 . 
68. Salemi S, D'Amelio R. Could autoimmunity be induced by vaccination? Int Rev Immunol. 2010;29(3):247-269.

69. Lecendreux M, Maret S, Bassetti C, Mouren MC, Tafti
M. Clinical efficacy of high-dose intravenous immunoglobulins near the onset of narcolepsy in a 10-year-old boy. J Sleep Res. 2003;12(4):347-348. 